\title{
The role of the subelytral cavity in water loss in the flightless dung beetle, Circellium bacchus (Coleoptera: Scarabaeinae)
}

\author{
FRANCES D. DUNCAN \\ School of Physiology, Faculty of Health Sciences, University of the Witwatersrand, 7 York Road, Parktown 2193, South Africa; \\ e-mail: duncanfd@physiology.wits.ac.za
}

Key words. Subelytral cavity, water loss, discontinuous gas exchange cycle, respiration, Scarabaeidae, Circellium bacchus

\begin{abstract}
Circellium bacchus is a flightless telecoprid (ball-rolling) dung beetle, endemic to the afrotropical region, where it is found in a few restricted populations in the eastern Cape of South Africa. Its apterous condition and large size (mass ranges from 6 to $12 \mathrm{~g}$ ) are considered to be adaptations to a semi-arid habitat. This beetle is active in the sun for long periods, walking between widely scattered dung pats, thus is under selection pressure to reduce water loss.

C. bacchus has eight spiracles on each side of the body. The metathoracic spiracle and six abdominal spiracles open into the subelytral cavity, which is closed. The mesothoracic spiracle is the largest and most exposed, occurring ventrally in the membrane connecting the prothorax and mesothorax.

When at rest a cyclic form of respiration, known as discontinuous gas exchange cycle, is used by C. bacchus, releasing a burst of carbon dioxide approximately once an hour when the spiracles open for about 33 minutes. Flow-through respirometry was used to measure water loss from the thorax (being the head, prothorax and mesothorax) and elytral case (containing the metathorax and abdomen) separately. The total water loss of C. bacchus could be divided up as $65 \%$ cuticular water loss from the thorax, $35 \%$ cuticular water loss from the elytral case, $4 \%$ respiratory water loss from the thorax and no measurable respiratory water loss from the elytral case. $1.51 \mu \mathrm{g}$ of water is lost for every $\mu 1$ of $\mathrm{CO}_{2}$ emitted during respiration in the thorax. Thus, the main avenue for both respiration and respiratory water loss is via the mesothoracic spiracles, suggesting that the primary function of the subelytral cavity is not to reduce respiratory water loss.
\end{abstract}

\section{INTRODUCTION}

The success of terrestrial insects is attributed to their ability to cope with a loss of water to the surrounding air and a limited and often an unpredictable supply of water (Hadley, 1994a). To cope with the evaporation of water, insects have developed physiological and morphological resistance to desiccation. The subelytral cavity, an airfilled space between the abdomen and sealed elytra, which is found in many arid-adapted beetles, has been considered an important structure which helps these beetles reduce their rate of water loss (Cloudsley-Thompson, 1975). Because the abdominal spiracles open into the cavity it maintains air at high humidity, thereby reducing the water lost during respiration (Ahearn, 1970; Zachariassen, 1991). This gave rise to the current hypothesis that the subelytral cavity evolved primarily to conserve water. Both Nicholson et al. (1984) and Zachariassen (1991) recorded low total evaporative water loss from the elytral cases of tenebrionid beetles (Onymacris plana and Phrynocolus petrosus respectively). However, these findings have always been confounded by the difficulty of determining the exact source of the water. Only recently, due to improved equipment, has it become possible to accurately separate respiratory water loss from cuticular transpiration.

The aim of this study was to estimate the differences in cuticular and respiratory water loss from the elytral case and anterior region of an arid-adapted beetle. In beetles, the first pair of spiracles occurs on the mesothorax, with the next seven to nine pairs on the metathorax and abdominal segments, covered by the elytra. Therefore the elytral case encloses the third thoracic segment and the entire abdomen. Two previous studies have managed to divide a tenebrionid beetle into sections and measure the water loss from each section (Cooper, 1983; Zachariassen, 1991). However, due to their experimental set-up, they were unable to measure respiratory water loss directly. Bosch et al. (2000) measured respiratory water loss directly in the beetle, Omorgus radula, but did not determine the separate contributions of the thorax and abdomen.

Zachariassen et al. (1987) suggested that the respiratory water loss is the dominant component of water loss in tenebrionid and carabid beetles from arid habitats in East Africa. However, Hadley (1994b) has shown that respiratory water loss rates may be lower than the cuticular water loss rates. Nevertheless, any reduction in respiratory water loss will help reduce overall water loss. A cyclic form of respiration referred to as the discontinuous gas exchange cycle (for reviews see Kestler, 1985; Lighton 1994, 1996; Wasserthal, 1996) is one means by which beetles may be able to reduce respiratory water loss. The discontinuous gas exchange cycle is a cyclic discontinuity in external gas exchange which typically consists of three periods (Miller, 1981; Kestler, 1985). These are; a closed (C) period where the spiracles are shut, which prevents both respiratory water loss and gas exchange. Oxygen levels in the tracheae drop while $\mathrm{CO}_{2}$ is largely buffered in the tissues and haemolymph. This is followed by the flutter (F) period, during which slight 


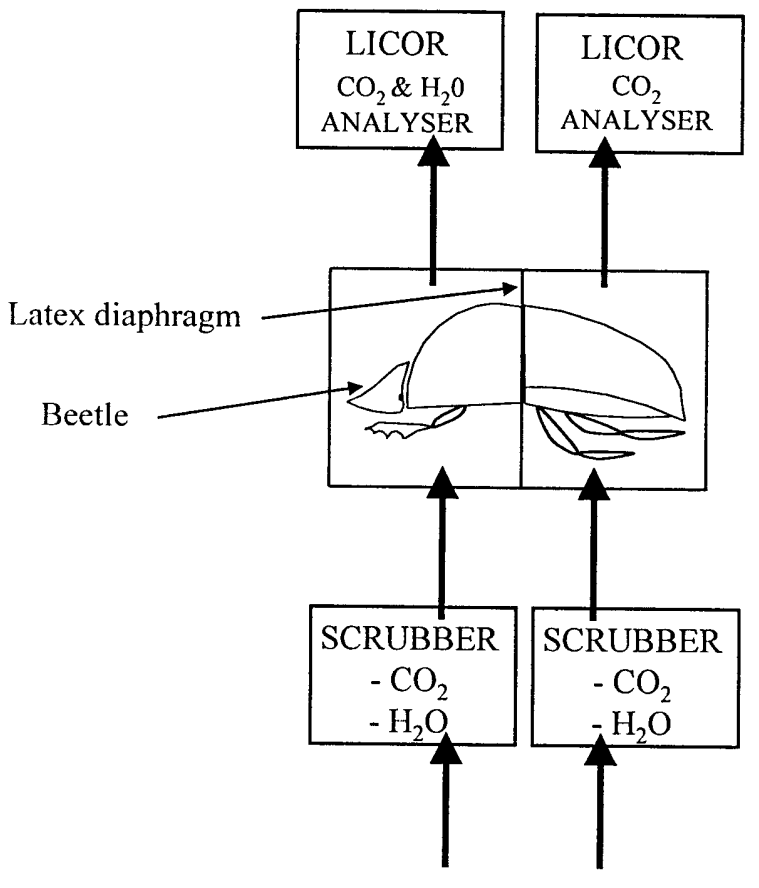

AIR

Fig. 1. Diagram of the experimental set-up, showing the beetle divided into an anterior part and posterior part and flowthrough system for each part separately. (See text for details).

opening of the spiracles on an intermittent basis allows some normoxic $\mathrm{O}_{2}$ uptake through the spiracles by diffusion and convection, but little $\mathrm{CO}_{2}$ or water vapour is lost. The final period, the $\mathrm{CO}_{2}$ burst (B) period, is triggered when the accumulation of $\mathrm{CO}_{2}$ from respiring tissues causes some or all of the spiracles to open widely. The rapid unloading of $\mathrm{CO}_{2}$ should minimise the time the spiracles are open and therefore reduce water vapour loss. Thus all periods are considered important to reduce respiratory water loss.

For this study I chose an arid dwelling beetle which possesses a subelytral cavity and uses discontinuous gas exchange cycle for respiration. Circellium bacchus (F.) (Scarabaeinae: Canthonini) is a flightless telecoprid (ballrolling) dung beetle, endemic to the afrotropical region, where it is found in a few restricted populations of the eastern Cape of South Africa (Chown et al., 1995). Telecoprid dung beetles detach a portion of dung from a dropping, roll it some distance away from the source and then bury it, or place it in a grass tussock. C. bacchus is assumed to be a poor competitor against other large, flying telecoprids, and is therefore confined to drier habitats. This beetle is active in the sun for long periods, walking between widely scattered dung pats, thus is under selection pressure to reduce water loss. Duncan and Byrne (2000), found an association in dung beetles between the aridity of the habitat and respiration pattern, with $C$. bacchus being an extreme example of the discontinuous gas exchange cycle.

The apterous condition and large size (mass ranges from 4 to $12 \mathrm{~g}$ ) of $C$. bacchus are considered adaptations to an arid habitat. Fortunately its large size also makes division of the beetle easier and therefore measurement of its respiratory water loss possible. C. bacchus has eight spiracles on each side of the body. The metathoracic spiracle and six abdominal spiracles open into the subelytral cavity, which is closed. The mesothoracic spiracle is the largest and most exposed, occurring ventrally in the membrane connecting the prothorax and mesothorax, behind the coxal cavities of the prothoracic legs. In this position it opens into the "waist" between the thorax and abdomen. By dividing the beetle at its "waist", I was able to measure the water loss rates from the elytral case and the anterior region of the beetle separately and simultaneously. Thus the route of respiratory water loss and contribution to total water loss could be determined.

\section{MATERIAL AND METHODS}

Circellium bacchus adults were collected from the Addo Elephant National Park (33E30'S, 25E41'E) in the Cape Province, South Africa, with permission from the National Parks Board because of the conservation status of this species. The beetles were housed in 101 bins half filled with soil, in an insectary at $25^{\circ} \mathrm{C}$ with a $14: 10 \mathrm{~h}$ light:dark cycle. They were fed fresh cow dung weekly, and survived well for several months under laboratory conditions.

A flow-through respirometry system was used to measure $\mathrm{CO}_{2}$ and $\mathrm{H}_{2} \mathrm{O}$ emission in inactive beetles at room temperature $\left(23^{\circ} \mathrm{C}\right)$. The individual beetle to be tested was placed in a perspex respirometry chamber. The chamber was separated into two halves, together having a volume of approximately $250 \mathrm{ml}$. Both halves were made from a block of perspex with an internal cavity of approximately $40 \mathrm{~mm}$ diameter drilled out for the animal. Four holes at each corner allowed the two halves to be bolted together. The chamber halves were divided using a sheet of latex (dental dam 0.013-0.018 cm thick, The Hygenic Corporation) thus separating the respiratory chamber into two air-tight compartments. A small hole was cut into the latex sheet which formed a collar around the "waist" of the beetle. In this configuration the anterior part of the beetle (head, prothorax, mesothorax and forelegs) was in one compartment and the posterior part (elytral case, middle legs and hindlegs) was in the other. Each compartment could be sampled or ventilated through two stainless steel pipes attached to the respirometry equipment (Fig. 1). The entire configuration was tested for leaks, and the latex sheet was replaced for each measurement.

The flow-through system was set-up for each compartment separately, with each having its own source of air, flow controller and gas analyser. Room air, scrubbed of $\mathrm{CO}_{2}$ and $\mathrm{H}_{2} \mathrm{O}$ vapour by a Drierite/Ascarite column, was drawn through the compartment at $50 \mathrm{ml} \mathrm{min}{ }^{-1}$ (controlled by a calibrated Supelco flow meter) and then into either a Licor $\mathrm{CO}_{2}$ analyser (LI-6251) or Licor $\mathrm{CO}_{2} / \mathrm{H}_{2} \mathrm{O}$ analyser (LI-6262). The LI-6262 is a dualwavelength infrared absorbance analyser capable of measuring $\mathrm{CO}_{2}$ and $\mathrm{H}_{2} \mathrm{O}$ simultaneously to a resolution of 0.1 p.p.m. and $0.002 \mathrm{kPa}$, respectively. Bev-A-Line low permeability tubing was used to connect the components, and the distance from each compartment to the respective analyser was kept to the minimum and was identical. Readings of the volume of $\mathrm{CO}_{2}$ and/or $\mathrm{H}_{2} \mathrm{O}$ emitted were taken every $5 \mathrm{~s}$ (unless noted otherwise) and recorded using computerised data acquisition software (Datacan V, Sable Systems). Measurements were made on individual beetles that were weighed to $\pm 0.1 \mathrm{mg}$ (Precisa $160 \mathrm{~A}$ balance). The beetles were measured for a minimum of 6 hours in the dark. They were occasionally observed to ensure that they 


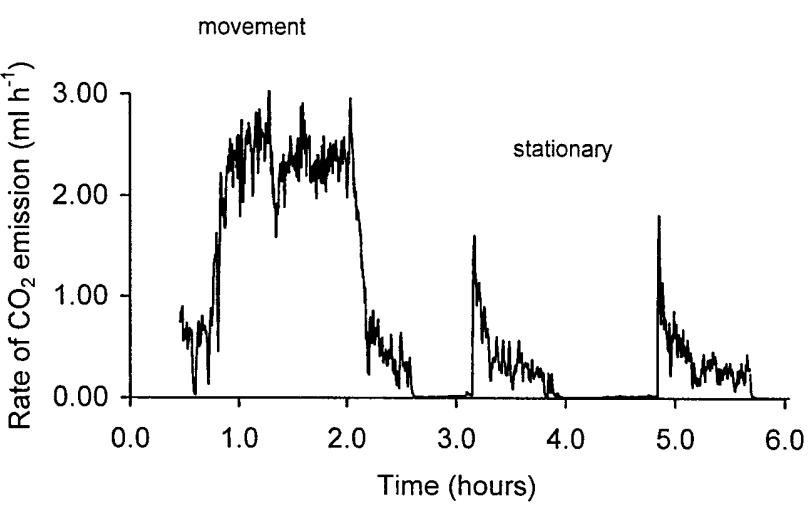

Fig. 2. Carbon dioxide emission from thorax region of a 9.677 $\mathrm{g}$ Circellium bacchus at $23^{\circ} \mathrm{C}$, showing the effects of movement on the discontinuous gas exchange cycles.

remained quiescent during sampling. After measurements, the beetles were weighed again.

Baseline drift of the analysers was corrected during analysis from measurements at the beginning and end of each trial with the respirometry chamber empty. All measurements were corrected to Standard Temperature and Pressure. The $\mathrm{CO}_{2}$ recordings were converted to rate of $\mathrm{CO}_{2}$ production $\left(\mathrm{CO}_{2}\right)$ in $\mathrm{ml} \mathrm{h}^{-1}$ and $\mathrm{H}_{2} \mathrm{O}$ data were converted to water loss rate in $\mathrm{mg} \mathrm{h}^{-1}$. The discontinuous gas exchange cycle (DGC) characteristics (as given in Table 1) were calculated as follows. The DGC frequency (= burst frequency) is calculated by determining the number of peaks of $\mathrm{CO}_{2}$ per second, and the DGC duration is one complete cycle (ie. closed, flutter and burst period). The mean rate of $\mathrm{CO}_{2}$ or $\mathrm{H}_{2} \mathrm{O}$ emission is the mean value over several complete discontinuous gas exchange cycles. To measure the emission volume, integration of the area under the curve against hours was performed.

Data are represented as means \pm standard deviation. Sample size $(\mathrm{n})$ is indicated in the text as either representing individua beetles or in the case of gas exchange characteristics and burst period water loss, three to ten discontinuous gas exchange cycles per beetle. Regression analysis was done by the least squared method.

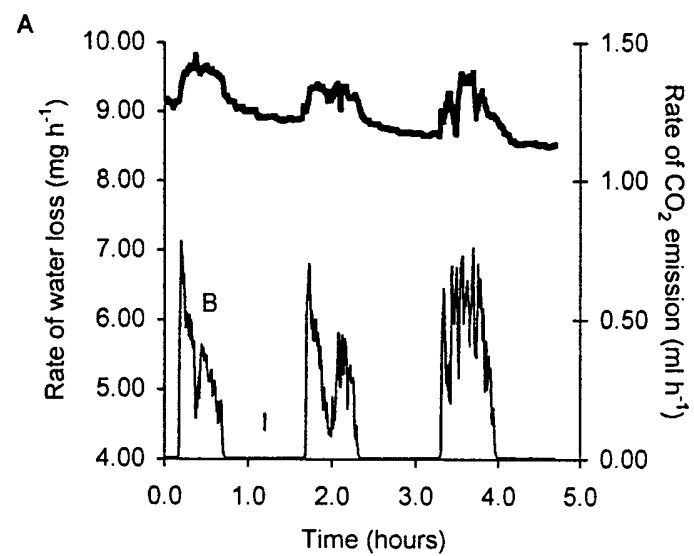

RESULTS

It was not possible for activity to be monitored continuously during the measurements. However, during intermittent visual observations while beetles were recorded, I noted that even slight movements were accompanied by noticeable changes in the pattern of $\mathrm{CO}_{2}$ emission from the thorax (Fig 2). In all experiments the $\mathrm{CO}_{2}$ emission from the thorax was measured to ensure that the data came from inactive beetles and any measurements showing activity were excluded from the analysis.

The trace of $\mathrm{CO}_{2}$ and $\mathrm{H}_{2} \mathrm{O}$ emission from the same beetle (mass $=7.296 \mathrm{~g}$ ) with separate recordings of the anterior part, referred to as thorax (consisting of head, pro- and meso-thorax regions), and elytral case (metathorax and abdomen) is shown in Fig. 3. All three beetles showed a similar pattern and the results are summarised in Table 1. There is a clear discontinuous gas exchange cycle pattern from the thorax similar to that recorded by Duncan and Byrne (2000) for whole specimens of C. bacchus (Fig. 3A), with a definite burst and closed periods but no or limited flutter period. In Table 1, the interburst period refers to the region between two $\mathrm{CO}_{2}$ bursts ie. between the burst period, as there was no distinct closed and flutter periods (Fig. 3A). During the burst period of the $\mathrm{CO}_{2}$ emission trace, a corresponding increase in water loss occurs. These bursts of $\mathrm{H}_{2} \mathrm{O}$ loss are the respiratory water loss from the mesothoracic spiracles while open, and the recording of water loss between these bursts corresponds to the cuticular water loss as the spiracles are closed during this period. (I have assumed that in the interburst period there is only uptake of $\mathrm{O}_{2}$ and no loss of $\mathrm{CO}_{2}$ and $\mathrm{H}_{2} \mathrm{O}$; see Kestler, 1985). In Fig. 3B, the $\mathrm{CO}_{2}$ emission from the elytral case is less than that of the thorax and no distinct cycles can be seen. The $\mathrm{CO}_{2}$ trace does, however, show some periodic increases but there is no corresponding increase in water loss. The random fluctuations in the water loss trace can be attributed to instrument noise. Thus for the elytral case it was not possible to separate respiratory water loss from cuticular

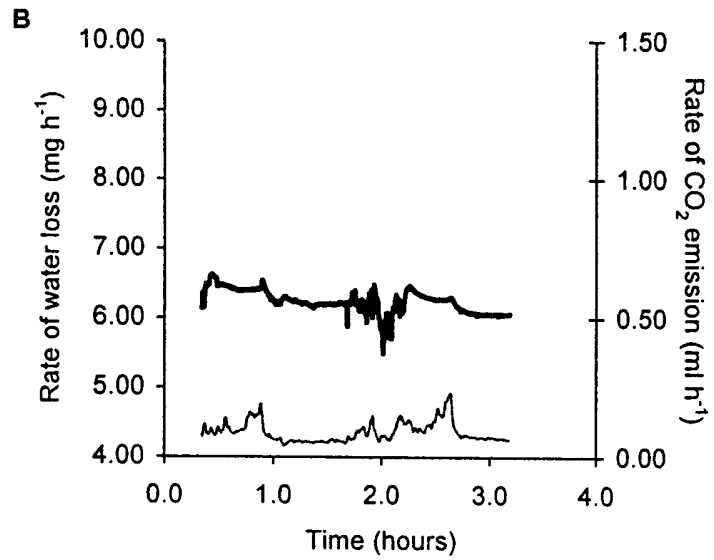

Fig. 3. Water loss (upper trace, broader line) and $\mathrm{CO}_{2}$ emission (lower trace) from a $7.296 \mathrm{~g}$ Circellium bacchus at $23^{\circ} \mathrm{C}$ while motionless. A - recording taken from thorax region (ie. head, prothorax and mesothorax). B marks the burst period and I marks the interburst period of the discontinuous gas exchange cycle; B - recording taken from the elytral case (ie. metathorax and abdomen) of the same beetle. 


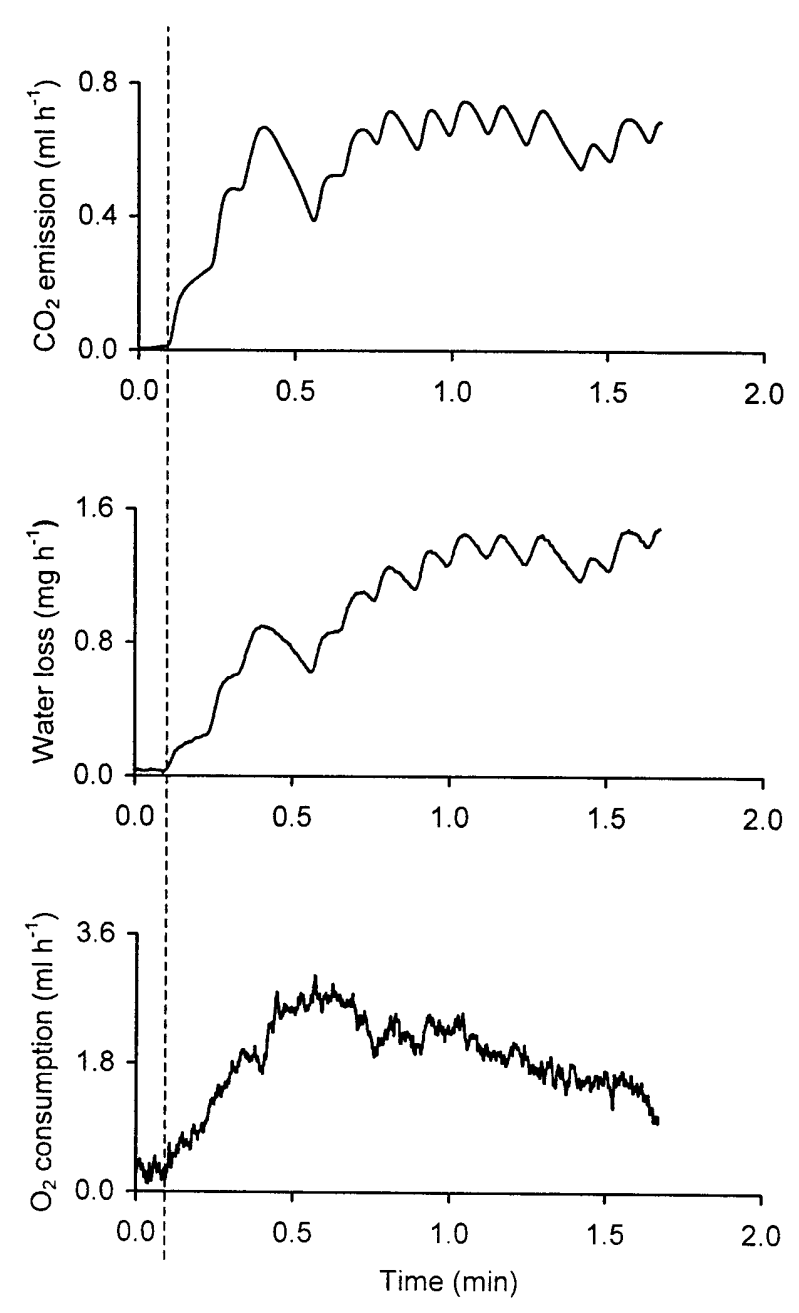

Fig. 4. Recordings of $\mathrm{CO}_{2}$ emission (upper trace), water loss (middle trace) and $\mathrm{O}_{2}$ uptake (lowest trace) taken every 0.06 seconds from the thorax region in Circellium bacchus. The delay in the $\mathrm{O}_{2}$ recording has been corrected (the $\mathrm{O}_{2}$ analyser was further downstream of the beetle). The water loss trace only indicates the increase above the cuticular water loss. The dotted line indicates the opening of the spiracles.

water loss. $65.1 \%$ of the total water loss and $71.3 \%$ of total $\mathrm{CO}_{2}$ emission came from the thorax (Table 1).

Fig. 4 shows that on opening the mesothoracic spiracles, three events occurred instantaneously viz. $\mathrm{CO}_{2}$ emitted, $\mathrm{H}_{2} \mathrm{O}$ lost and $\mathrm{O}_{2}$ is taken up. The same event was not observed for the elytral case, thus expired air is not leaving through a single aperture above the anus in an intermittent pattern.

By combining the water loss rate $\left(\mathrm{mg} \mathrm{h}^{-1}\right)$ from the thorax and elytral cavity (Table 1), the average total water loss rate for the three beetles (mean mass of $7.195 \mathrm{~g} \pm$ 2.81 ) in this study is $10.1 \mathrm{mg} \mathrm{h}^{-1} \pm 4.25$, which compares well with that found by Chown et al. (1995) for C. bacchus. In their study of water loss rates using the gravimetric method they found an average rate of $14 \mathrm{mg} \mathrm{h}^{-1}$ \pm 1.9 (range of 8.1-34.8) from beetles of average mass $6.489 \mathrm{~g} \pm 0.332$.

Separating the water loss into cuticular and respiratory components (assuming no respiratory water loss from the
TABLE 1. Relative contribution of thorax and elytral case to water loss in Circellium bacchus (mean mass $=7.192 \mathrm{~g} \pm 2.54, \mathrm{n}=3$ )

\begin{tabular}{|c|c|c|c|}
\hline Variable & Thorax & Elytral case $^{1}$ & $\begin{array}{c}\text { Ratio } \\
\text { thorax: } \\
\text { elytral } \\
\text { case }\end{array}$ \\
\hline DGC frequency $(\mathrm{mHz})$ & $0.20 \pm 0.03$ & - & \\
\hline DGC duration (min) & $84.87 \pm 13.36$ & - & \\
\hline $\mathrm{CO}_{2}\left(\mu \mathrm{g} \mathrm{g}^{-1} \mathrm{~h}^{-1}\right)$ & $15.57 \pm 3.76$ & $7.28 \pm 4.87$ & $2.84: 1$ \\
\hline $\mathrm{H}_{2} \mathrm{O}\left(\mu \mathrm{g} \mathrm{g}^{-1} \mathrm{~h}^{-1}\right)$ & $922.98 \pm 287.25$ & $594.56 \pm 378.41$ & $2.04: 1$ \\
\hline $\mathrm{H}_{2} \mathrm{O}\left(\mathrm{mg} \mathrm{h}^{-1}\right)$ & $6.42 \pm 2.17$ & $3.68 \pm 2.34$ & $2.14: 1$ \\
\hline Interburst $\mathrm{CO}_{2}\left(\mu 1 \mathrm{~g}^{-1} \mathrm{~h}^{-1}\right)$ & $0.69 \pm 0.36$ & - & \\
\hline Interburst $\mathrm{H}_{2} \mathrm{O}\left(\mu \mathrm{g} \mathrm{g}^{-1} \mathrm{~h}^{-1}\right)$ & $896.64 \pm 288.61$ & - & \\
\hline Burst $\mathrm{H}_{2} \mathrm{O}$ loss $\left(\mu \mathrm{g} \mathrm{g}^{-1}\right)$ & $30.37 \pm 14.64$ & - & \\
\hline \multicolumn{4}{|l|}{ Peak burst water loss } \\
\hline increase $\left(\mu \mathrm{g} \mathrm{g}^{-1} \mathrm{~h}^{-1}\right)^{2}$ & $50.06 \pm 18.07$ & - & \\
\hline
\end{tabular}

${ }^{1}$ Note that no $\mathrm{CO}_{2}$ burst periods were observed from the elytral case.

${ }^{2}$ Refers to the increase above interbust or cuticular water loss levels.

elytral case): $64 \%$ of total cuticular water loss is from the thorax while $36 \%$ is from the elytral case. Respiratory water loss could only be measured from the thorax and contributed $4 \%$ to total water loss, but $6 \%$ of thoracic water loss.

\section{DISCUSSION}

Several functions have been suggested for the subelytral cavity, one being to help reduce respiratory water loss (Cloudsley-Thompson, 1975). For this to occur, the abdominal spiracles which open into this cavity should be the main site for gas exchange. The assumption being that when the spiracles are open to allow gas exchange to occur the respiratory passages would be exposed to humid air and lose less water through diffusion. In this study, using C. bacchus, I have shown that for the posterior part of the body, including the elytral cavity, respiratory water loss cannot be separated from cuticular water loss, and that respiratory water loss is probably negligible as less than one third of the expired air leaves from this site (Duncan and Byrne, manuscript submitted). This suggests that the spiracles inside the subelytral cavity are not the major site of gas exchange.

Table 2 shows the results from studies on beetles in which the respiratory water loss rates from the elytral case were estimated separately from the thorax. In this study I attempted to measure respiratory water loss directly, whereas in the other three studies it was measured using indirect methods, which may partially explain some of the differences. In Onymacris plana, Nicolson et al. (1984) found the cuticular water loss rate from the elytral case was the same as that measured from the tip of the abdomen. They assumed that expired air leaves through a single aperture above the anus and by measuring water loss rates from this area they would determine the contribution of elytral respiratory water loss and cuticular water loss to total water loss rates. However, they were unable 
TABLE 2. Relative contribution of cuticular and respiratory transpiration to total water loss. The thorax region refers to the head, prothorax and mesothorax; the elytral case refers to the metathorax and abdomen sections of the beetles.

\begin{tabular}{lcccc}
\hline Species & $\begin{array}{c}\text { Body } \\
\text { region }\end{array}$ & $\begin{array}{c}\text { Percent total water loss } \\
\text { cuticular respiratory }\end{array}$ & $\begin{array}{c}\text { Tem } \\
\text { pera- } \\
\text { ture }\end{array}$ \\
\hline Circellium bacchus $^{1}$ & thorax & $62.95 \pm 9.95$ & $4.12 \pm 2.94$ & $23^{\circ} \mathrm{C}$ \\
& elytral case & $34.89 \pm 11.38$ & & \\
Eleodes armata & thorax & \} 70.5 & 4.5 & $30^{\circ} \mathrm{C}$ \\
& elytral case & & 25 & \\
Eleodes armata $^{3}$ & thorax & \} 64 & 10.7 & $30^{\circ} \mathrm{C}$ \\
& elytral case & & 25 & \\
Phrynocolus petrosus $^{4}$ & thorax & 322.1 & 68.8 & $23^{\circ} \mathrm{C}$ \\
& elytral case & & 9.1 & \\
\hline
\end{tabular}

${ }^{1}$ This study, ${ }^{2}$ from Ahearn (1970), ${ }^{3}$ from Cooper (1983), ${ }^{4}$ from Zachariassen (1991).

to simultaneously measure whether $\mathrm{CO}_{2}$ was being eliminated through this aperture.

In the thorax, an increase in $\mathrm{CO}_{2}$ emission during the interburst period resulted in a corresponding increase in water loss [linear regression: water loss rate $\left(\mathrm{mg} \mathrm{g}^{-1} \mathbf{h}^{-1}\right)=$ $0.36+853.9 \mathrm{CO}_{2}$ emission $\left(\mathrm{mg} \mathrm{g}^{-1} \mathrm{~h}^{-1}\right), \mathrm{r}^{2}=0.73, \mathrm{P}<$ $0.001]$. Thus, there could be a small but undetectable amount of respiratory water loss occurring from the elytral case when there is an increase in $\mathrm{CO}_{2}$ emission.

In C. bacchus the water loss rates were less from the elytral case (Tables 1 and 2). However from this study it was not possible to ascertain whether; the presence of humid air in the subelytral space, a more regular surface structure and possibly less surface area, or a difference in cuticular permeability (Loveridge, 1980) in this region is responsible for the difference measured. The contribution of the elytral cavity to total water loss in C. bacchus was less than half, similar to that found in O. plana by Nicolson et al. (1984).

Estimates of the contribution of respiratory water loss to total water loss in beetles have ranged from $6.5 \%$ in the trogid beetle, Omorgus radula (Bosch et al., 2000), to $70 \%$ in the tenebrionid beetle, Phrynocolus petrosus (Zachariassen, 1991). The use of discontinuous gas exchange cycles in respiration could lower respiratory water loss (Kestler, 1985) and the relative contribution of respiratory transpiration in insects that are known to exhibit discontinuous gas exchange cycles ranges from $1.9 \%$ to $13 \%$ (Hadley, 1994b). The value estimated for $C$. bacchus $(4.12 \%)$ is within this range.

By using discontinuous gas exchange cycles in the mesothoracic spiracles, $C$. bacchus is reducing the amount of time the respiratory passages are exposed to dry air. The opening of spiracles is due to the build up of $\mathrm{CO}_{2}$ in the haemolymph (Harrison, 2001), but the closure may have been induced to reduce water vapour loss. Although the mesothoracic spiracles are the most exposed in C. bacchus, in their situation behind the coxal cavities of the prothoracic legs they do not open directly to outside air and some water vapour may be retained.

Another means of reducing respiratory water loss is to increase $\mathrm{CO}_{2}$ emission efficiency. This has been used by
C. bacchus as the ratio of water lost to $\mathrm{CO}_{2}$ emitted during the burst period is markedly lower than that reported for other arid-dwelling insects. In C. bacchus $1.51 \mu \mathrm{g}$ of $\mathrm{H}_{2} \mathrm{O}$ is lost for every $\mu 1$ of $\mathrm{CO}_{2}$ (Table 1) compared to ants; 4.8 in Cataglyphus bicolor (Lighton, 1994), 3.25 in Pogonomyrmex rugosus alates (Lighton et al., 1993), 5.37 in P. rugosus workers and 5.29 in P. occidentalis workers (Quinlan \& Lighton, 1999) and approximately 5 in the trogid beetle Omorgus radula (Bosch et al., 2000). Respiratory water loss in C. bacchus is kept to a minimum as indicated by the small increase in peak burst water loss (Table 1).

\section{CONCLUSION}

In C. bacchus the rate at which water is lost through respiration has been reduced, such that it is only a small component of total water loss. This arid-adapted beetle does not seem to use the subelytral cavity to reduce respiratory water loss but uses discontinuous gas exchange cycles through the thoracic spiracles with a high $\mathrm{CO}_{2}$ emission frequency. Thus the hypothesis that the subelytral cavity evolved primarily as a water conservation adaptation is questioned.

ACKNOWLEDGEMENTS. I thank James Keegan and Marcus Byrne for advice and help with the experimental design, Graham Kerley for collecting the beetles, National Parks Board for allowing the collection, Duncan Mitchell for valuable discussions and Nico Douths for care of the beetles. Financial support came from the University of the Witwatersrand via the Communication and Behaviour Research Group.

\section{REFERENCES}

AHEARN G.A. 1970: The control of water loss in desert tenebrionid beetles. J. Exp. Biol. 53: 573-595.

Bosch M., Chown S.L. \& Scholtz C.H. 2000: Discontinuous gas exchange and water loss in the keratin beetle Omorgus radula: further evidence against the water conservation hypothesis? Physiol. Entomol. 25: 309-314.

Chown S.L., Scholtz C.H., Klok C.J., Joubert F.J. \& Coles K.S. 1995: Ecophysiology, range contraction and survival of a geographically restricted African dung beetle (Coleoptera: Scarabaeidae). Funct. Ecol. 9: 30-39

Cloudsley-Thompson S.L. 1975: Adaptations of arthropods to arid environments. Annu. Rev. Entomol. 20: 261-283.

COOPER P.D. 1983: Components of evaporative water loss in the desert tenebrionid beetles Eleodes armata and Cryptoglossa verrucosa. Physiol. Zool. 56: 47-55.

Duncan F.D. \& BYrne M.J. 2000: Discontinuous gas exchange in dung beetles: patterns and ecological implications. Oecologia 122: 452-458.

HADLEY N.F. 1994a: Water Relations of Terrestrial Arthropods. Academic Press, San Diego, 356 pp.

HADLEY N.F. 1994b: Ventilatory patterns and respiratory transpiration in adult terrestrial insects. Physiol. Zool. 67: 175-189.

HARRISOn J.F. 2001: Insect acid-base physiology. Anmu. Rev. Entomol. 46: 221-250.

KESTLER P. 1985: Respiration and respiratory water loss. In: Hoffmann K.H. (ed.): Environmental Physiology and Biochemistry of Insects. Springer-Verlag, Berlin, pp 137-183.

LIGHTON J.R.B. 1994: Discontinuous ventilation in terrestrial insects. Physiol. Zool. 67:142-162. 
Lighton J.R.B. 1996: Discontinuous gas exchange in insects Annu. Rev. Entomol. 41: 309-324.

Lighton J.R.B., Garrigan D.A., Duncan F.D. \& Johnson R.A 1993: Spiracular control of respiratory water loss in female alates of the harvester ant Pogonomyrmex rugosus. J. Exp. Biol. 179: 233-244.

LOVERIDGE J.L. 1980: Cuticular water relations techniques. In Miller T.A. (ed.): Cuticle Techniques in Arthropods. Springer-Verlag, New York, pp. 301-366.

MrLLeR P.L. 1981: Ventilation in active and inactive insects. In: Herreid C.F. (ed.): Locomotion and Energetics in Arthropods. Plenum, New York, pp. 367-390.

Nicolson S.W., Lorw G.N. \& EDNEY E.B. 1984: Use of a ventilated capsule and tritiated water to measure evaporative water losses in a tenebrionid beetle. J. Exp. Biol. 108: 477-481.
Quinlan M.C. \& Lighton J.R.B. 1999: Respiratory physiology and water relations of three species of Pogonomyrmex harvester ants (Hymenoptera: Formicidae). Physiol. Entomol. 24: 293-302.

WASSERTHAL L.T. 1996: Interaction of circulation and tracheal ventilation in holometabolous insects. Adv. Insect Physiol. 26: 297-351.

ZACHARIASSEN K.E. 1991: Routes of transpiratory water loss in a dry-habitat tenebrionid beetle. J. Exp. Biol. 157: 425-437.

Zachariassen K.E., Andersen J., Malom G.M.O. \& Kamau J.M.Z. 1987: Transpiratory water loss and metabolism of beetles from arid areas in East Africa. Comp. Biochem. Physiol. 86: $403-408$.

Received December 4, 2001; revised March 11, 2002; accepted March 21, 2002 